\title{
Hands-on Explorations as Background Research for First-Year Design Projects
}

\author{
A. Trivett, J. Rathlin \\ Department of Mechanical and Mechatronics Engineering \\ University of Waterloo, 200 University Avenue, Waterloo, ON N2L 3G1
}

\begin{abstract}
Collectively and individually, first-year students in Mechanical Engineering lack familiarity with real mechanical systems. Individual students have noted that they have not grown up able to simply "take stuff apart". As a result, the mechanical engineering undergraduates have minimal skills or knowledge of common mechanical devices. The foundations course for the Department of Mechanical and Mechatronics at the University of Waterloo has adopted the role of giving new students opportunities to interact with hardware in an "Engineering Clinic" environment.

This paper will provide a preliminary work-inprogress report on the activities and the role these activities played in the student experience. The paper will report on the delivery of the activities, and the initial student reactions to the hands-on activities in this context.
\end{abstract}

Keywords: engineering clinic, mechanical engineering, hands-on, hardware skills, engine dissection, first-year engineering,

\section{INTRODUCTION}

Students entering Mechanical Engineering at the University of Waterloo have achieved high-school grade averages well above $90 \%$. Looking at student resumes which they have developed in the first two weeks of their semester; it is evident that many students have excellent academic credentials, similar volunteer experience, and work experience in retail or service.

What they lack is often basic background in mechanical engineering. Clearly, we cannot expect a teenager with $90 \%+$ high school grades to have fixed farm equipment, repaired cars, or rebuilt bicycles. These sorts of mechanical skills seem to be less and less common in the first-year students. The design of first-year courses in mechanical engineering have long identified this need to provide experience for students coming in with variable levels of familiarity with the profession [1].

Employers frequently comment on the lack of handson skills. Even industries employing students in an office environment consider that an engineer should have some hardware familiarity. Anecdotes from the Waterloo Cooperative Education and Career Advancement office include stories of employers who ask students to explain what a Robertson screwdriver is, or the difference between two different screw threads.

The response from the engineering education community must be to provide these opportunities within the program. This paper describes the clinic activities and the student outcomes from those activities.

\section{HANDS-ON RESEARCH}

The philosophical underpinning of using real, physical objects and considering them as linked to the conceptual framework of technology has been the subject of extensive literature, reviewed and extended by Svensson and Ingerman [3]. While there are very clear cultural and historical factors, the use of objects as metaphors is well established, as is their recognition as systems of technology. Svensson and Ingerman have provided an extensive review of the philosophy captured within technological objects, and shown a rich opportunity to link the physical world with the ideas behind it. Their interviews of Swedish students focus on form and function, but do not address origin or conception of artifacts [3].

Using technological artefacts for teaching engineering has also been reported extensively. In most cases, the use of hardware is discussed in the realm of "reverse engineering” as in [2]. In other examples, the technology is presented to first-year students as general skill, or background knowledge that all students need to acquire in order to be successful in engineering [2].

The first-year cornerstone design course in Mechanical Engineering at the University of Waterloo is a teamoriented discovery course. Students are asked to develop designs in response to an authentic "Request for Proposals". The project trajectory is intended to let the students discover their chosen field of study rather than be delivered content from the podium. In keeping with the "discovery" of concepts, hands-on activities were offered as "research" for the design project. In keeping 
with the concept that hardware represents more than just the specific object, the hardware activities were presented as a subject to write about, and the hardware itself was described as embodying the work of mechanical engineers, and thus the engineering profession.

Students were introduced to real hardware in three “engineering clinic activities". Each activity required more than one session. In each activity, the graded task was to report observations of the hardware they examined in a memo to their design teammates. The motivation for students was that this activity was "research" into the profession and mechanical devices to help inform their designs.

In their first encounter, students were engaged in dissecting commercial radio-controlled toy cars. They were asked to find where in the cars were embodiments of "Mechanical Engineering". Later, they were presented with a wide array of broken or obsolete mechanical devices and challenged to discover what the parts were, what they were supposed to do, and if they were broken. Finally, they were presented with working 6hp singlecylinder gasoline engines and asked to take the engines apart, sketch the components, and then rebuild them. After each of the activities, students were required to write reports to their team members explaining what they observed, and how their observations might relate to their evolving design concepts.

\section{THE CLINIC ACTIVITIES}

The ME100 course in which the activities were embedded is delivered in two sections, each with approximately 100 students. One section of the course is "4-stream", a cohort that will be embarking upon their first co-op work term at the end of the first semester in University. The second cohort is "8-stream", and these students have their first co-op work experience after two semesters on campus.

The mandatory co-op component to the program means that students are genuinely starting their co-op job search within days of their first class. It is imperative that students begin to develop some practical, marketable skills to aid in finding their first co-op job. Having some minimal hands-on skill has been seen by employers as an important basic asset in co-op students of mechanical engineering.

The clinic activities started with examination of a toy, and then moved to consumer products, and finally an industrial object.

\subsection{Traxxas Car Exploration}

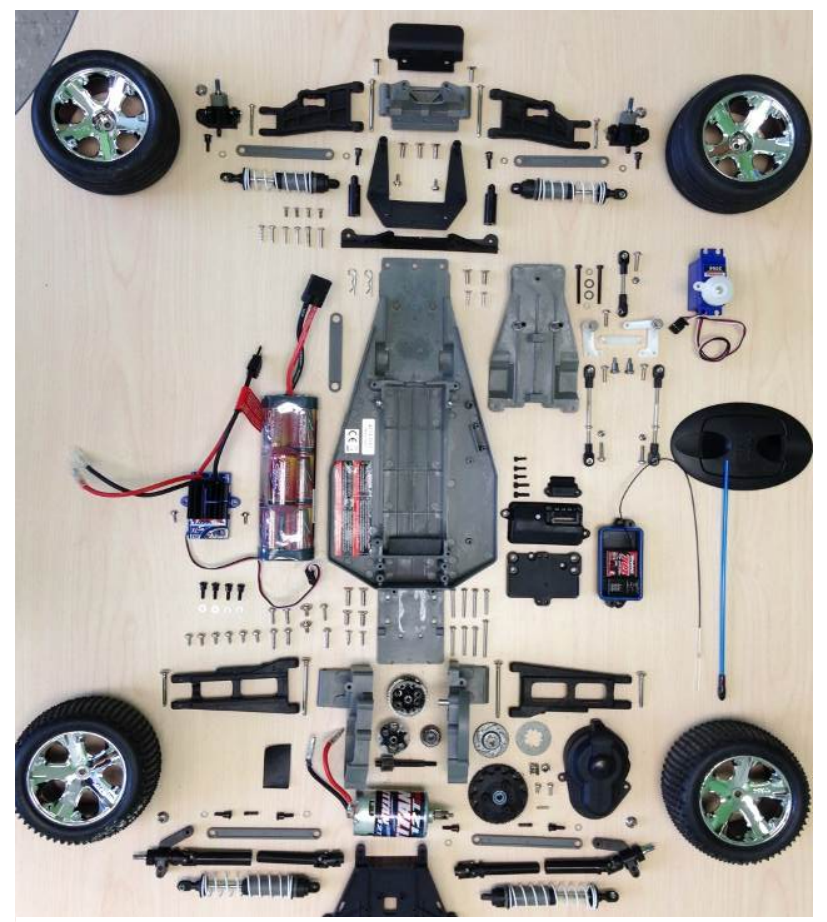

Figure 1: the Traxxas Radio Controlled cars were dissected to reveal all the components which represent mechanical engineering design.

In the Mechanical and Mechatronics Department at the University of Waterloo, the field of mechanical engineering is divided along the same lines as the research groups in the department. There is a fluids group, a thermal engineering group, a controls group, a solid mechanics group, a materials engineering group. Each of these is described, and the research done by faculty is shown as examples for students. After the student teams were created in ME100, and the major project was introduced, students were asked to read the department website in preparation for the activity.

In the first clinic activity, each student team was presented with a Traxxas Radio Controlled car (figure 1). They were told to go outside and play with the car.

After they had driven their cars for 10 or 15 minutes, they brought them back into the lab. The teams of six divided themselves into two subgroups. One group of three watched while the others disassembled the car. As the disassembly students worked, the observing students took notes, and looked specifically for examples of the different sub-disciplines of mechanical engineering in the car.

Students observed that the dampers in the suspension system represented fluids engineering, the cooling vanes on the motor controller represented thermal engineering, 
the suspension system represented solid mechanics, or the plastic of the chassis represented materials engineering.

At the end of the disassembly, the students switched roles. Those who disassembled watched on as the others proceeded to rebuild. The first group was not allowed to touch the tools or the car, but could offer written or verbal guidance.

At the end of the activity, students were required to write a brief technical note to their team explaining what they saw in the car, and what they observed as examples of engineering. They answered a number of open-ended questions such as "is the car mechanical engineering?"

\subsection{Repair Cafe}

Throughout the $4^{\text {th }}$ to the $7^{\text {th }}$ weeks of the 13 -week semester, students were required to attend a "repair café" activity for two visits. The stated purpose of the task for students was to look at broken or obsolete products, figure out how they worked, find if they were in fact functional, and if not try to find why they were not.

While it was originally hoped the students might "repair" some of the hardware, this turned out to be often impossible, and ultimately irrelevant to the activity. The act of simply taking things apart proved to be a major challenge. After running the activity for the first teams, we subsequently encouraged students to simply explore the hardware, and not worry about repair or reassembly.

They attended the first of two scheduled sessions, which were carried out in a small engineering clinic space with only 15 students at each time. Each student had 3 or more small devices ranging from old computer keyboards, cooling fans, bicycle parts, wheels, printers, valves, turntables, CD changers, mixers and more. The components were collected from campus labs, as well as from local community recycle stores.

The community store had a large stock of donated equipment that was not working, and was too complex or difficult to repair. The use of the hardware in this course was diverting it from being taken to e-waste or solid waste. In the end, most of the equipment was eventually sent to waste, but it had served a useful instructional purpose.

Students wrote their observations of hardware and how components might relate to a conceptual design that their team was developing for the major design project. The writing, which was a key component of the course, was addressed to the rest of the team, and it formed the only graded portion of the activity. Student performance in the hands-on activity was not graded.

After their first session, students were required to book a second session within a few weeks. In their second session, they were able to accomplish much more, now being familiar with the activity and the tools. They typically came to the second activity with a specific list of items they wanted to examine, rather than being given a random assortment. This resulted in more relevant components to their design project ideas.

\subsection{IC Engine exploration}

For the past 3 years in the MME department, students have been dissecting one of a stock of 80 single-cylinder 6hp snowblower engines. The engines have been used in both the mechatronics and mechanical foundation courses, and in third- year thermodynamics, fluid mechanics, machine design, and manufacturing courses. The popularity of exploring the workings of these small engines has seen the activity expand into the outreach programs to high school students, and to Women in Engineering outreach programs.

The activity, as it was run in the ME100 course, was similar to the first two clinic activities. Teams scheduled their own time in the engineering clinic for one session over a 2-week period from weeks 9-10 in the semester.

In the activity, each team was given two engines and

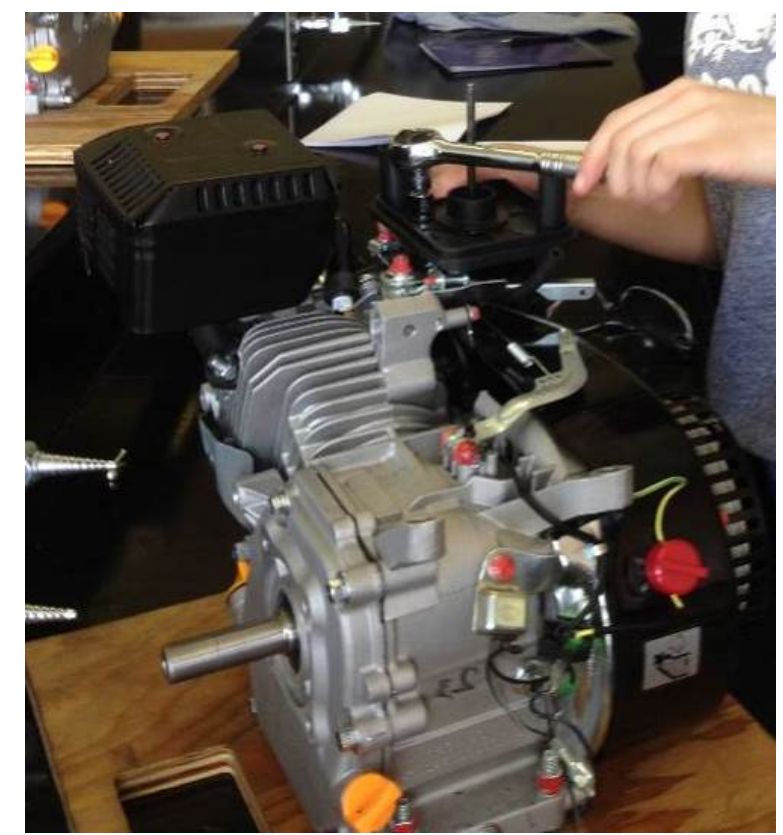

Figure 2: The single-cylinder 6-hp snowblower engines were used as examples of industrial equipment. Students explored the engines, removing major assemblies to see the mechanical design within.

tools to take it apart. The students were required to have viewed a video before coming of the engine dissection. They were given instruction regarding how far to tear down by the clinic staff and permitted to start. Due to the difficulty of reassembly, they were not able to remove the piston from the cylinder, or the crankshaft. They did remove the carburetor, valve cover, head and valves, 
tappets, one end of the main shaft bearing, and crankcase cover.

By the end of their time, students re-assembled the engine and performed an integrity test. The test required students to crank the engine and measure cylinder pressure, crank angle and spark to ensure that it was correctly rebuilt, and should run if fueled.

Through the activity, the students were prompted to compare a "real" engineering device like an engine with the toys and consumer goods they had previously examined.

\section{RESULTS}

Students who have never dissected complex mechanical devices coming into a mechanical engineering program are lost when faced with genuine design. Even having the language to ask the right questions is difficult for many incoming students to mechanical engineering.

In one example from the ME100 design projects, consider a team of 5 students want to build a small gantry crane system that would use a rack and pinion gear drive system on a small shaft to travel in one axis, while a leadscrew would travel in the perpendicular axis. In trying to help the students to develop their idea, not only was the above language foreign to them (in effect, they had never seen or heard the word "lead-screw" or "rack and pinion"), they had never seen the devices these names describe. This is an almost impossible starting point for helping a student design team.

Instructors, in this example, were unable to effectively explain to the students what they needed; nor help them picture what the words meant. Grasping for examples that they may have noticed in their 18 years of living in Canada was a difficult task requiring patience.

The students in this case had a chance to take apart an obsolete inkjet printer and see the mechanisms, different from what they envisioned for their design, but providing the same function. After handling the device, and looking for examples of lead-screws with help from the instructor, and practice building components, a working design became achievable.

In order to develop designs, students need to be able to picture in their minds the devices that may be examples or precursors to what they want to create. Failing their ability to both imagine it and describe it using engineering language, having either the language, or the images would be a start.

Student evaluation of the course was relatively low due to many comments on the online peer-discussion forums and the extensive workload in writing. However, regardless of the low satisfaction with the course, they appeared to dissociate the course as a whole from the clinic activities. The most frequent comment in the course evaluations was that they "loved the clinic activities" and that they wanted more of them.

\section{CONCLUSION}

In the first semester mechanical engineering course, a primary learning outcome is for students to be able to explain the field of mechanical engineering. While it has been observed that student ability and interest in literature research is minimal, the proof of mechanical engineering design is represented in the devices and systems that our professional colleagues have created. Those products exist all around us. Rather than have students read about the range of mechanical engineering, we have used the actual products as the subject for research. In the ME100 clinic activities, students observed real devices, and argued which represented engineering and which did not.

The University of Waterloo faculty of engineering is organized in a cohort structure for students. The same 100 students in the first semester cohort should substantially remain together until graduation in $42 / 3$ years. With such a strong cohort organization, it is somewhat surprising that students surveyed in their $3^{\text {rd }}$ and $4^{\text {th }}$ years claim that they don't really know many others in their class. A show-of-hands survey by the authors of students in a typical $3^{\text {rd }}$ year mechanical engineering class showed that very few could claim to know the names of more than 10 or 15 other students in their class. This is despite the fact that they have always been with the same cohort of students.

An outcome of the hands-on activities described in this paper was to strengthen the sense of class community in the first semester. Students found that they shared a common experience, one in which very few were skilled. The shared sense of challenge in the class is hoped will carry on through their following terms.

This paper is a preliminary report of work-inprogress. Using practical clinic activities to help give students hands-on exposure will continue in future years. As the activities become more mature, future work will quantify the outcomes of such activities.

\section{References}

[1] Ambrose, Susan A., Amon, Cristina H., Systematic Design of a First-Year Mechanical Engineering Course at Carnegie Mellon University, Journal of Engineering Education, Vol. 86( 2), pp.173 - 181, 1997

[2] Collier-Reed, B. I., Jennifer M. Case, Cedric Linder, The experience of interacting with technological artefacts, European Journal of Engineering Education, 34(4), Vol 34(4), pp.295-303, August 2009 
Proc. 2015 Canadian Engineering Education Association (CEEA15) Conf.

[3] Svensson, M., Åke Ingerman, Discerning technological systems related to everyday objects: mapping the variation in pupils' experience, International Journal of Technology and Design Education, Vol 20(3), pp.255-275, August 2010
[4] Wood, Kristin L., Jensen, Daniel, Bezdek, Joseph, Otto, Kevin N., Reverse Engineering and Redesign: Courses to Incrementally and Systematically Teach Design, Journal of Engineering Education, Vol 90( 3), pp 363- 374, 2001 